\title{
TBX2 over-expression promotes nasopharyngeal cancer cell proliferation and invasion
}

\author{
Yan Lvi, ${ }^{1,}$, Meng $\mathrm{Si}^{2, *}$, Nannan Chen ${ }^{3, *}$, Ya $\mathrm{Li}^{3, *}$, Xingkai Ma ${ }^{4}$, Huijun Yang ${ }^{4}$, Ling \\ Zhang ${ }^{1}$, Hongyan Zhu ${ }^{1}$, Guang-yin $\mathrm{Xu}^{1,3}$, Ge-ping $\mathbf{W u}^{1,4}$ and $\mathrm{C}$. $\mathrm{Cao}^{3}$ \\ ${ }^{1}$ Center of Translational Medicine, The First People Hospital of Zhangjiagang City, Soochow University, Suzhou, China \\ ${ }^{2}$ Department of Neurology, The Second Affiliated Hospital of Soochow University, Suzhou, China \\ ${ }^{3}$ Institute of Neuroscience, Soochow University, Suzhou, China \\ ${ }^{4}$ Department of Otolaryngology, The First People Hospital of Zhangjiagang City, Soochow University, Suzhou, China \\ *These authors have contributed equally to this work \\ Correspondence to: Ge-ping Wu, email: gordon-wu@qq.com \\ C. Cao, email: caocong@suda.edu.cn \\ Guang-yin XU, email: guangyinxu@suda.edu.cn
}

Keywords: TBX2, nasopharyngeal cancer, invasion, proliferation, siRNA

Received: December 06, $2016 \quad$ Accepted: March 12, $2017 \quad$ Published: April 13, 2017

Copyright: Lv et al. This is an open-access article distributed under the terms of the Creative Commons Attribution License 3.0 (CC BY 3.0), which permits unrestricted use, distribution, and reproduction in any medium, provided the original author and source are credited.

\section{ABSTRACT}

TBX2 is a member of the $T$ box transcription factor family. Its expression and potential biological functions in nasopharyngeal cancer (NPC) cells are studied here. We showed that TBX2 mRNA and protein expression was significantly elevated in multiple human NPC tissues, as compared with that in adjacent normal tissues. Knockdown of TBX2 by targeted-siRNA significantly inhibited proliferation and invasion of NPC cells (CNE-1 and HONE-1 lines). Meanwhile, TBX2 knockdown also induced G1-phase cell cycle arrest. At the molecular level, we discovered that expressions of several tumor suppressor genes, including p21, p27, phosphatase with tensin homology (PTEN) and E-Cadherin, were increased dramatically after TBX2 knockdown in above NPC cells. Collectively, our results imply that TBX2 overexpression promotes NPC cell proliferation and invasion, possibly via silencing several key tumor suppressor genes.

\section{INTRODUCTION}

Nasopharyngeal cancer (NPC) is a rare type of head and neck squamous cell carcinoma (HNSCC). NPC could be caused by a combination of factors, including Epstein-Barr virus infection, environmental influences, and heredity [1-3]. NPC is endemic in Southeast Asia and southern China. In 2008 , over 84,400 cases of NPC were diagnosed, and $80 \%$ of the cases occurred in Asia [4]. Even with the development of modern radiation therapy, distant metastasis will develop in $30-40 \%$ of patients within 4 years [5]. Improved understanding of NPC progression and the development of novel therapies is still urgently needed.

TBX2 is a member of the T box transcription factor family proteins, which are characterized by a highly conserved $\mathrm{T}$ box DNA binding domain [6]. TBX2 is fundamental to the morphogenesis of various tissues and organs, such as limbs [7, 8], heart [9], bone [10,11] and mammary glands [12]. Existing evidences have linked TBX2 to tumorigenesis. TBX2 expression is up-regulated in a wide range of cancers, including melanoma [13], pancreatic cancer [14], bladder cancer, breast cancer [1517], colorectal cancer [18] and lung cancer [19].

TBX2 functions as a repressor of transcription, which inhibits promoter activity of a number of cancer-suppressing genes. For example, it can facilitate the bypass of senescence by repressing transcription of $C d k n 2 a(p 19 A R F)$ and $C d k n 1 a$ (p21WAF1) [17]. TBX2 could also promote anchorageindependence growth and increase resistance to apoptotic stimuli in p53-negative SW13 adrenocortical carcinoma cells [20]. Furthermore, TBX2 is shown to directly repress E-Cadherin transcription, and to increase motility 
and invasiveness of malignant breast cancer cells [21]. Meanwhile, TBX2 directly targets checkpoint proteins p21 and p27 to promote cell cycle progression [21,22]. Despite the importance of TBX2 in tumorigenesis of various cancers, the expression and biological functions of TBX2 in NPC are still largely unknown. In the current study, we report that TBX2 expression is up-regulated in clinical NPC tissue samples. Knockdown of TBX2 in the NPC cells inhibits cancer cell proliferation and invasion.

\section{RESULTS}

\section{TBX2 expression in human NPC tissues}

To investigate the expression of TBX2 in NPC, TBX2 mRNA expression was assessed in RNA samples that were isolated from 35 pairs of NPC tumor tissues and paired adjacent normal tissues. Quantitative realtime PCR assay (qRT-PCR) results in Figure 1A showed that the average TBX2 mRNA value in NPC tissues was significantly $(P<0.0001)$ higher than in normal samples. TBX2 protein expression was also higher in NPC tissues, which was determined by Western blot assay (Figure 1B) and immunohistochemistry (IHC) staining assay (Figure 1C). For the Western blot assay, blot images analyzing four representative paired-tissues were presented (Figure $1 \mathrm{~B}$, upper panel). All the blot data of 35 paired-tissues were integrated for statistics analysis (Figure 1B, lower panel). Twenty of the 35 paired-tissues showed fine IHC staining (Figure 1C). Sixteen of them (80\%) demonstrated high TBX2 expression, and representative images were shown (Figure 1C). These data suggest that TBX2 protein and mRNA expression is significantly increased in NPC tissues.
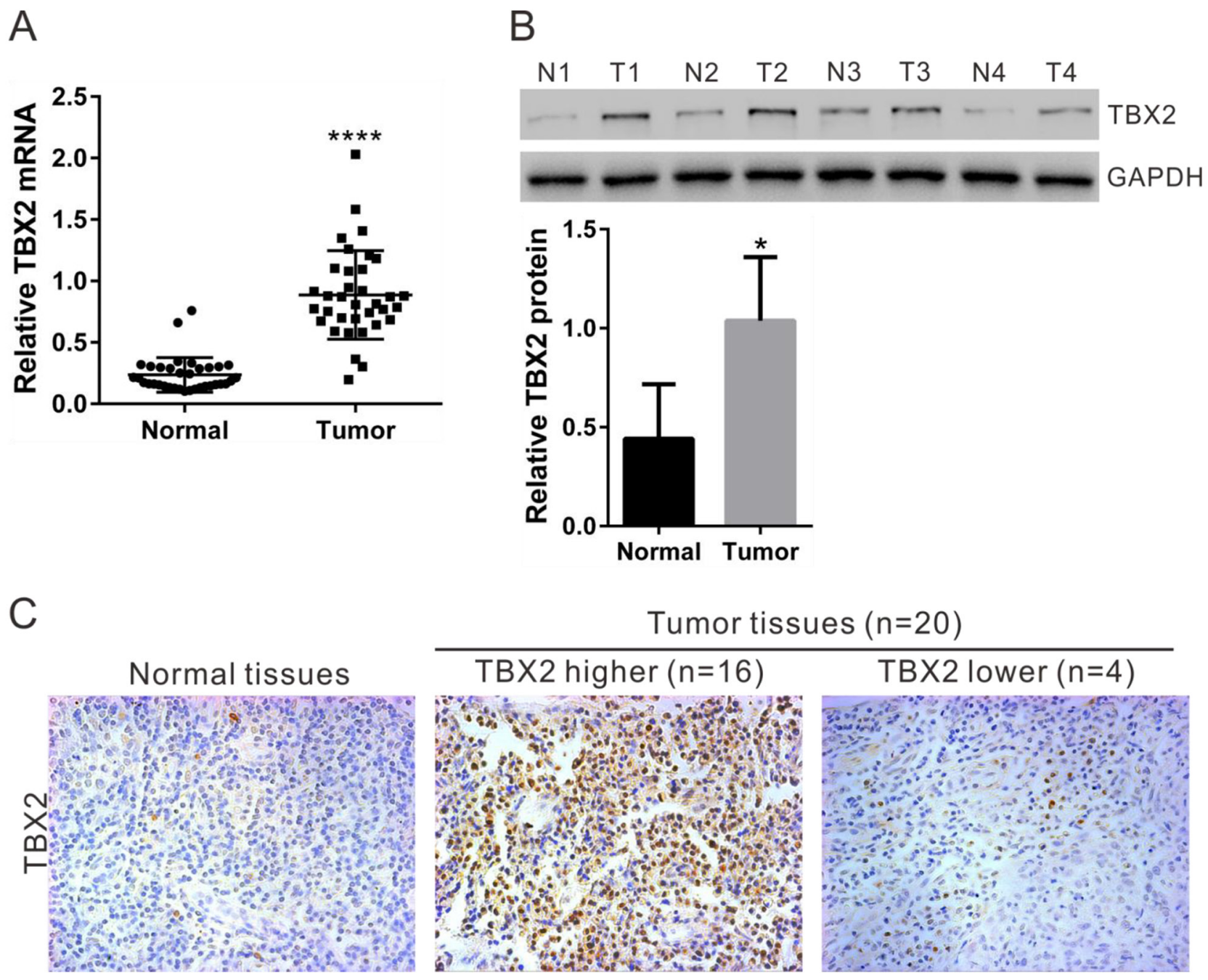

Figure 1: TBX2 expression in human NPC tissues. (A) The mRNA expression of TBX2 in NPC ("Tumor") and paired surrounding normal tissues ("Normal", n=35) were examined by qRT-PCR. (B) Representative TBX2 protein expression in NPC (T1, T2, T3 and T4) and normal tissues (N1, N2, N3 ad N4). GAPDH was used as a loading control. (C) Immunohistochemistry staining of TBX2 in NPC and normal tissues. ${ }^{* * * *} P<0.0001$ vs. "Normal" tissues (A). ${ }^{*} P<0.01$ vs. "Normal" tissues (B). 


\section{siRNA knockdown of TBX2 in NPC cells}

We also tested expression of TBX2 in a panel of NPC cell lines, including C666-1, CNE-1, HONE-1, CNE2 and SUNE-1. As shown in Figure 2A, among all the tested cell lines, CNE-1 and HONE-1 showed highest expression of TBX2 (both protein and mRNA). In order to study the function of TBX2 in NPC cell behaviors, we transfected TBX2 siRNAs (siRNA1, siRNA2 and siRNA3, with non-overlapping sequence) or control siRNA (siNC) into CNE-1 and HONE-1 NPC cells. To determine the effect of siRNA on TBX2 expression, qRT-PCR and Western blotting were performed. Relative to "Mock" or siNC-transfected cells, transfection of the TBX2 siRNAs in CNE-1 (Figure 2B) and HONE-1 (Figure 2C) cells significantly decreased TBX2 mRNA and protein expression. Among all the tested siRNAs, TBX2 siRNA1 had the highest knockdown efficiency, and was thus chosen for further experiments.

\section{TBX2 knockdown inhibits NPC cell proliferation and cell-cycle progression}

The CCK-8 assay was applied to determine the function of TBX2-siRNA1 on the proliferation of CNE1 (Figure 3A) and HONE-1 NPC cells (Figure 3B). As demonstrated, TBX2 siRNA1 transfection indeed significantly inhibited above NPC cell proliferation at $48 \mathrm{~h}$ and $72 \mathrm{~h}$ (Figure $3 \mathrm{~A}$ and $3 \mathrm{~B}$ ). Accumulating evidence has suggested a function of TBX2 in promoting cell cycle progression [23]. We then examined whether TBX2 siRNA1 could also inhibit cell cycle progression.
Propidium iodide (PI) staining of DNA content was applied to analyze cell cycle progression, and results showed that the G0/G1 phase percentage in TBX2 siRNA1-transfected CNE-1 cells (Figure 3C) and HONE1 cells (Figure 3D) was $63.47 \pm 0.80 \%$ and $62.95 \pm 0.22 \%$, as compared to $46.69 \pm 1.24 \%$ and $46.80 \pm 2.35 \%$ in siNC cells. Concurrently, S-phase and G2/M-phase cells were decreased in NPC cells transfected with TBX2 siRNA1 (Figure $3 \mathrm{C}$ and $3 \mathrm{D}$ ). These results show that TBX2 knockdown inhibits NPC cell proliferation and cell-cycle progression.

\section{Silencing of TBX2 inhibits NPC cell in vitro migration}

In order to study whether TBX2 siRNA could change the invasion ability of CNE-1 cells and HONE1 cells, we transfected TBX2 siRNA1 again in these cell lines. In vitro invasion assay was performed in Matrigelpre-coated Transwell. Results showed that, as compared to cells transfected with siNC, the invasive potential of CNE-1 cells and HONE-1 cells with TBX2 siRNA1 was dramatically inhibited (Figure 4A and 4B). The number of migrated cells decreased by about $52 \%$ (for CNE1 cells) and 68\% (for HONE-1 cells) following TBX2 siRNA knockdown (Figure 4A and 4B). Therefore, TBX2 knockdown also inhibits NPC cell in vitro migration. Notably, for the migration assay, mitomycin C $(5 \mu \mathrm{g} / \mathrm{mL})$ was always added to exclude the possible influence of cell proliferation. As shown in Supplementary Figure 1, treatment with mitomycin $\mathrm{C}(5 \mu \mathrm{g} / \mathrm{mL})$ failed to decrease CCK-8 viability OD of CNE-1 cells (Supplementary
A
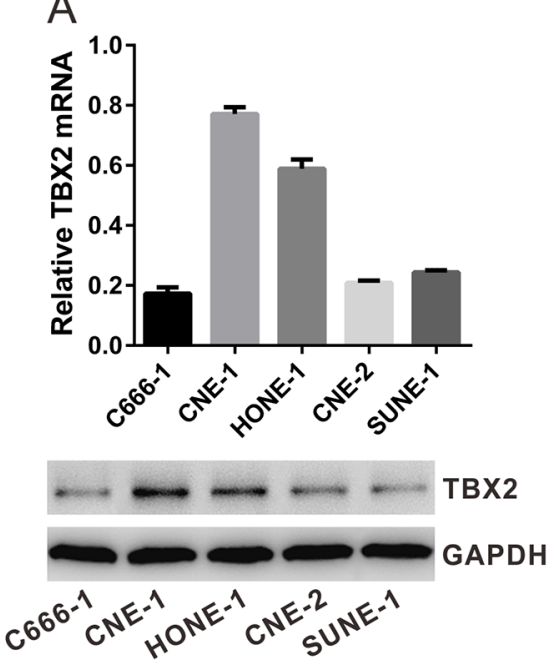

B
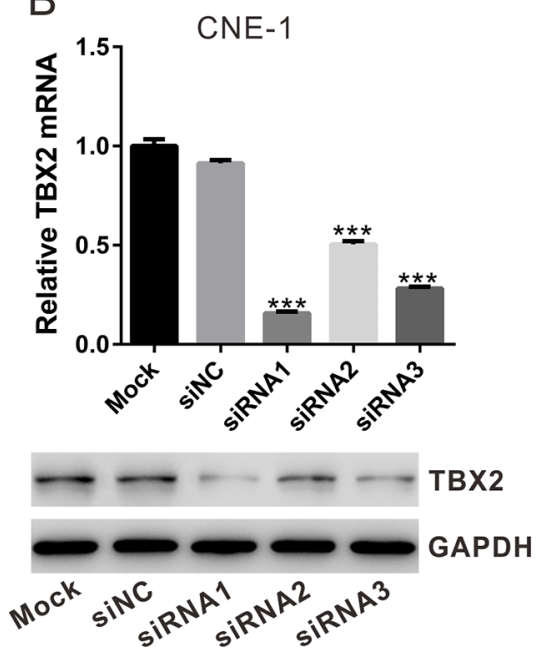

C
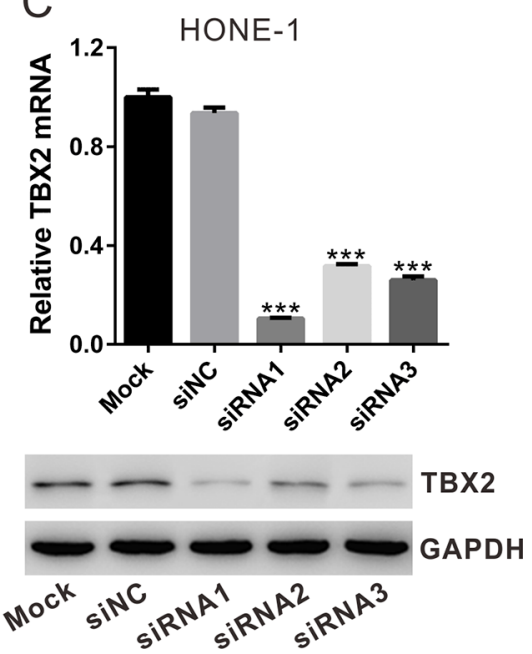

Figure 2: siRNA knockdown of TBX2 in NPC cells. (A) mRNA (upper panel) and protein (lower panel) levels of TBX2 in five listed NPC cell lines. (B, C) Identification of TBX2 knockdown efficiency by qRT-PCR and Western blotting in CNE-1 cells and HONE1 cells. All data are representative results of three independent experiments. Mock: non-treated cells; siNC: cells transfected with siNC; siRNA1-3: cells transfected with TBX2 siRNA1, siRNA2 or siRNA3. $* * * P<0.001$ vs. siNC. 

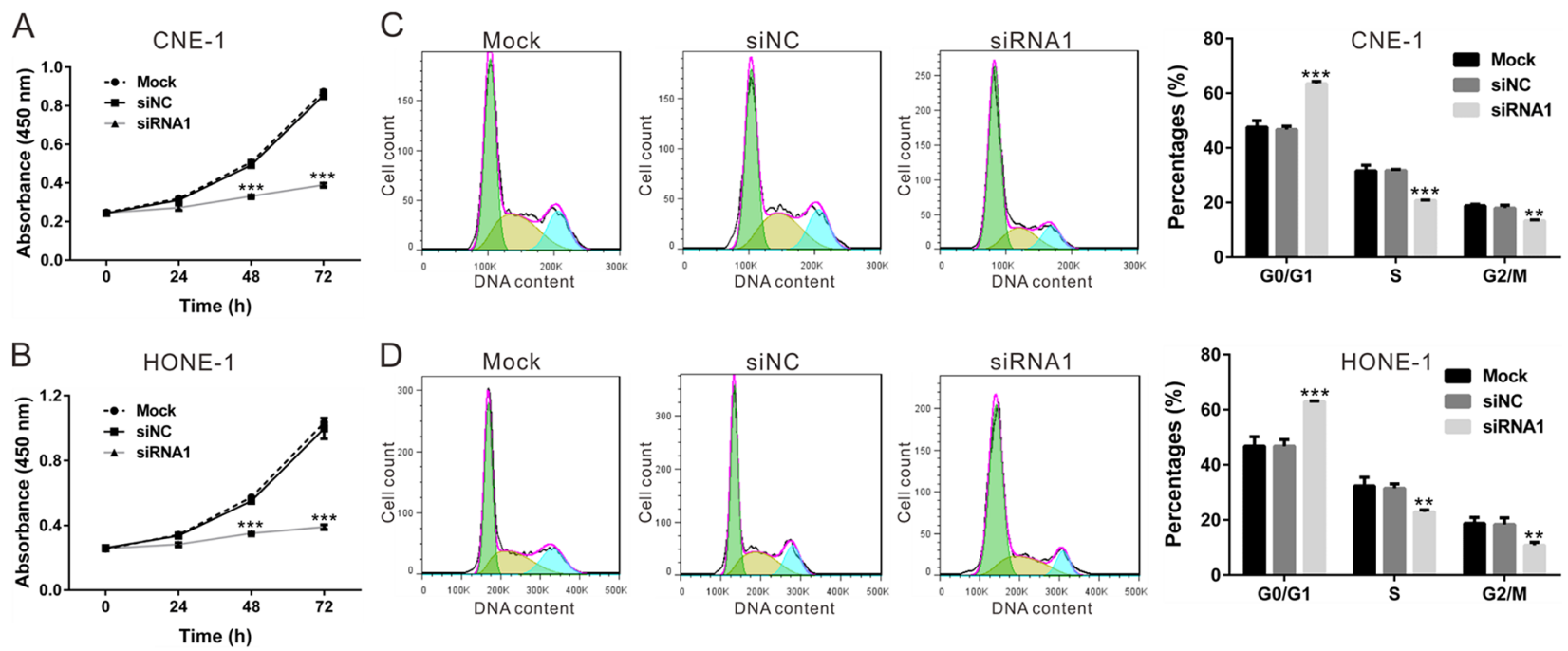

Figure 3: TBX2 knockdown inhibits NPC cell proliferation and cell-cycle progression. CNE-1 cells and HONE-1 cells were transfected with siNC or TBX2 siRNA1. (A, B) Cell viability was determined at indicated time points by CCK-8 assay. (C, D) At $48 \mathrm{~h}$ post transfection, cell cycle distribution analysis was performed after PI staining. All assays were performed in triplicate. All data are representative results of three independent experiments. Mock: non-treated cells; siNC: cells transfected with siNC; siRNA1: cells transfected with TBX2 siRNA1. $* * P<0.01, * * * P<0.001$ vs. siNC.
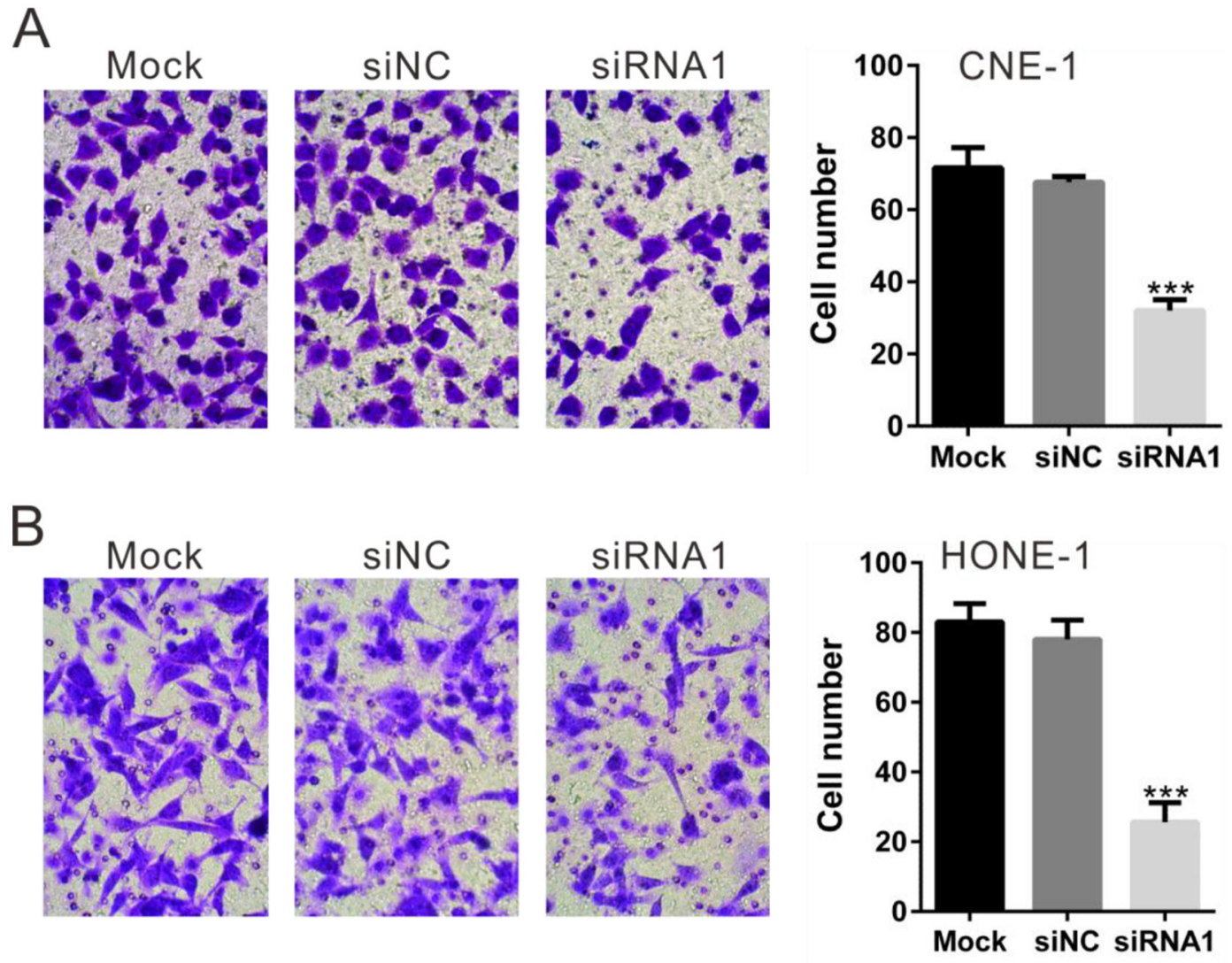

Figure 4: Silencing of TBX2 inhibits NPC cell in vitro migration. Invasion assay was carried out in Matrigel-coated Transwell chambers. Cells that migrated into the lower well were stained, photographed and counted. TBX2 silencing in CNE-1 cells (A) and HONE1 (B) cells notably inhibited cell invasion. All data are representative results of three independent experiments. Mock: non-treated cells; siNC: cells transfected with siNC; siRNA1: cells transfected with TBX2 siRNA1. $* * * P<0.001$ vs. siNC. 
Figure 1A) and HONE-1 cells (Supplementary Figure 1B). Further, CNE-1 and HONE-1 cell proliferation was indeed blocked with mitomycin $\mathrm{C}$ treatment, as the viable cell number was almost unchanged after culture for 12-48 hours (Supplementary Figure 1C and 1D).

\section{TBX2 siRNA knockdown increases expression of several key tumor-suppressors}

The above results demonstrated that TBX2 siRNA knockdown inhibits proliferation and migration of human NPC cells. Previous studies have suggested that TBX2 can repress tumor-suppressors phosphatase with tensin homology (PTEN) [24], p21 [25, 26], p27 [26] and E-Cadherin [21], thus promoting cell proliferation and invasion. We then tested the effect of TBX2 siRNA knockdown on the expression of the above genes. The qRT-PCR data showed that silencing TBX2 remarkably increased the mRNA expression of PTEN (increase by: CNE-1 cells, $184.8 \%$ and HONE-1 cells, 183.4\%), p21 (increase by: CNE-1 cells, 109.5\% and HONE-1 cells, 133.9\%), p27 (increase by: CNE-1 cells, 153.7\% and HONE-1 cells, 104.0\%) and E-Cadherin (increase by: CNE-1 cells, $143.4 \%$ and HONE-1 cells, 87.1\%) (Figure $5 \mathrm{~A}$ and $5 \mathrm{~B}$, left panels). Similar changes were obtained at protein levels, PTEN, p21, p27 and E-Cadherin protein expression was significantly increased in TBX2-silenced cells (Figure 5A and 5B, right panels). As expected, siNC showed no effect on protein and mRNA expression of above genes. These data together suggest that TBX2 siRNA knockdown increases expressions of several key tumor-suppressors, which could be responsible for NPC cell proliferation and migration inhibition.

\section{DISCUSSION}

Up-regulation of TBX2 has been reported in a wide range types of cancer [13-19]. In the present study, we reported that TBX2 mRNA and protein expression was significantly higher in NPC tissues samples than that in
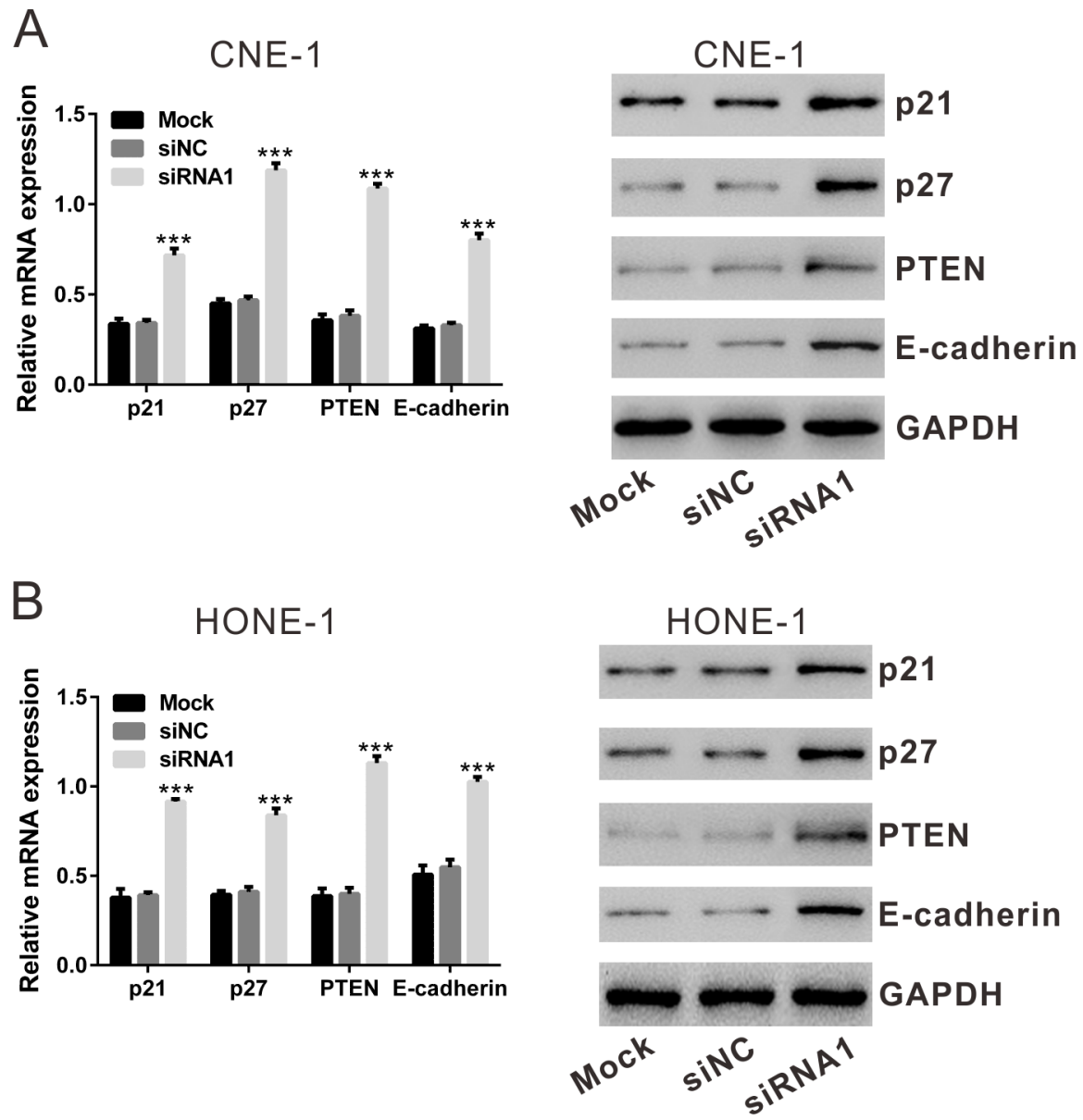

Figure 5: Effect of TBX2 siRNA1 on the mRNA and protein expression of p21, p27, PTEN and E-Cadherin by qRTPCR and Western blotting assay, respectively. (A), CNE-1 cells. (B), HONE-1 cells. Mock: non-treated cells; siNC: cells transfected with siNC; siRNA1: cells transfected with TBX2 siRNA1. $* * * P<0.001$ vs. siNC. 
Table 1: Primer sequences for quantitative PCR

\begin{tabular}{|c|c|c|}
\hline Primer & Primer sequence & Size (bp) \\
\hline $\begin{array}{l}\text { TBX2 } \\
(\mathrm{NM} 005994.3)\end{array}$ & $\begin{array}{l}\text { F: 5'- GACCCTGAGATGCCCAAACG -3' } \\
\text { R: 5'- GGTGCGGAAGGTGCTGTAAG -3', }\end{array}$ & 222 \\
\hline $\begin{array}{l}\text { p21 } \\
(\mathrm{NM} 000389.4)\end{array}$ & $\begin{array}{l}\text { F: 5'- TAGCAGCGGAACAAGGAG -3' } \\
\text { R: 5'-AAACGGGAACCAGGACAC -3' }\end{array}$ & 249 \\
\hline $\begin{array}{l}\text { p27 } \\
(\mathrm{NM} 004064.4)\end{array}$ & $\begin{array}{l}\text { F: 5'- GCTTGCCCGAGTTCTACTAC -3' } \\
\text { R: 5'- GCAGGTCGCTTCCTTATTCC -3' }\end{array}$ & 220 \\
\hline $\begin{array}{l}\text { PTEN } \\
(\text { NM_000314.6) }\end{array}$ & $\begin{array}{l}\text { F: 5'- ATTAGTGCTGTTGCTAGTTC -3' } \\
\text { R: 5'- GCAACAATCATTAGGCTTTC -3' }\end{array}$ & 194 \\
\hline $\begin{array}{l}\text { E-Cadherin } \\
(\mathrm{NM} 004360.3)\end{array}$ & $\begin{array}{l}\text { F: 5'- GAGAACGCATTGCCACATACAC -3' } \\
\text { R: 5'- AAGAGCACCTTCCATGACAGAC -3' }\end{array}$ & 164 \\
\hline $\begin{array}{l}\text { GADPH } \\
(\text { NM_001256799.2) }\end{array}$ & $\begin{array}{l}\text { F: 5' - CACCCACTCCTCCACCTTTG -3' } \\
\text { R: 5'- CCACCACCCTGTTGCTGTAG -3', }\end{array}$ & 110 \\
\hline
\end{tabular}

the adjacent normal tissues. Previous studies have implied a possible function of TBX2 up-regulation in promoting cell proliferation and invasion. Here, we also observed similar results in NPC cells, indicating that TBX2 might also promote proliferation and invasion of NPC cells.

Uncontrolled cellular proliferation is one of the main features of cancer. Here, siRNA knockdown of TBX2 in two NPC cell lines significantly decreased cancer cell proliferation, which was consistent with previous studies in heart cells [27], in melanoma cells [13] and rhabdomyosarcoma cells [28]. The checkpoint protein p21 is a well-known cyclin-Cdk inhibitor, which is vital for the G1-S progression [29]. Over-expression of p21 shall cause G1-S arrest [29]. Similarly, p27 is a potent inhibitor of cyclin D1-Cdk4 and cyclin A-Cdk2 protein kinase activity, which is related to p21 [22]. Exogenous expression of p27 is shown to induce G1-S arrest as well [22]. Both p21 $[25,26], \mathrm{p} 27$ [26] are the TBX2-targted proteins. In the current study, we showed that p21 and p27 were increased in TBX2-silenced NPC cells, that could explain the subsequent $\mathrm{G} 1$ arrest and proliferation inhibition.

$\mathrm{PI} 3 \mathrm{~K} / \mathrm{AKT}$ pathway is involved in the regulation of cell cycle progression and cellular growth [30]. Recent work has shown that TBX2 is a central component of the PTEN/PI3K/AKT signaling pathway in rhabdomyosarcoma cells by repressing PTEN [24]. Consistent with these findings, we showed that PTEN expression was increased in TBX2-silenced cells. Therefore, TBX2 may exert the cell proliferationpromoting functions via regulating PTEN/PI3K/AKT signaling pathway as well.

Cell invasion/migration is essential to the metastasis of cancer. Increased expression of E-Cadherin was shown to inhibit cell invasion [31]. Here, we discovered that TBX2 knockdown significantly increased E-Cadherin expression, and repressed in vitro invasion/migration of
NPC cells. Our results here are consistent with the findings in malignant breast cancer cells [21]. These results along with the mentioned previous studies suggest that TBX2 could promote cell proliferation and invasion of different cancer cells. Recent studies have also proposed a pivotal function of TBX2 in cell senescence [17]. It has been shown that TBX2 can inhibit Cdkn2a (p19ARF) promoter and suppress E2F1, Myc or HRAS-mediated induction of Cdkn2a (p19ARF) [17]. Therefore, it would be interesting to test potential effect of TBX2 in NPC cell senescence.

\section{MATERIALS AND METHODS}

\section{Clinical tissue specimens}

Paired human NPC tissues and matched normal tissues were collected from 35 written-inform consent patients underwent standard surgical procedures in The First People Hospital of Zhangjiagang City (Zhangjiagang, China). Tissue samples used for RNA isolation or protein extraction were immediately snap-frozen in liquid nitrogen and stored at $-80^{\circ} \mathrm{C}$. Other tissue samples for histological examination and immunohistochemistry staining were fixed using $10 \%$ buffered formalin. The experiment protocols were approved by the Institutional Review Committees of The First People Hospital of Zhangjiagang City and Soochow University.

\section{RNA isolation and quantitative RT-PCR (qRT-PCR)}

Total RNA was isolated from NPC tissues, normal tissues samples and cell lines with TRIzol reagents (Life Technologies), and then reversely transcripted to cDNA with the First-Strand cDNA Synthesis Kit (Thermo 
Fisher, Shanghai, China) following the manufacturers' instructions. The quantitative real-time PCR reactions were performed on a 7300 Real Time PCR machine (Applied Biosystems, Foster City, CA) with SYBR Green qPCR Master Mixes (Thermo Fisher). GAPDH gene was amplified as an internal control. The oligonucleotides used as PCR primers were listed in Table 1.

\section{Protein extraction and western blotting assay}

Cells or human tissue specimens were lysed via the described lysis buffer [32-34]. Aliquots of $40 \mu \mathrm{g}$ of total proteins from each treatment were separated by $10-12 \%$ SDS-PAGE gels and were transferred onto polyvinylidene difluoride (PVDF) membranes (Millipore, Bedford, MA), which were then blocked in $10 \%$ milk and incubated with specific primary and second antibodies. Antibody-antigen binding was detected with the enhanced chemiluminescence (ECL) detection system (Amersham Biosciences, Piscataway, NJ). Each band was quantified through Image J software (NIH). For the Western blot assay, each lane was loaded with exact same amount of quantified protein lysates (40 $\mu \mathrm{g}$ per sample). Same set of lysate samples were run in sister gels to test different proteins. Following antibodies were utilized: TBX2 (ab33298, Abcam, Cambridge, MA, 1:1000 dilution), PTEN (9552, Cell Signaling; Danvers, MA, 1:1000 dilution), E-Cadherin (3195, Cell Signaling, 1:1000 dilution), p21 (2946T, Cell Signaling, 1:2000 dilution), p27 (3688, Cell Signaling, 1:1000 dilution) and GAPDH (2188, Cell Signaling, 1:1000 dilution). Secondary antibodies (A0208, HRP-labeled Goat Anti-Rabbit IgG, Beyotime, 1:1000 dilution; A0216, HRP-labeled Goat Anti-Mouse IgG, Beyotime, 1:1000 dilution) were employed.

\section{Immunohistochemistry analysis}

TBX2 protein expression in tissue sections was detected by immunohistochemistry (IHC). Briefly, 5- $\mu \mathrm{m}$ sections were de-paraffinized in xylene (concentration over $99.0 \%$ ), rehydrated through a graded ethanol series, and antigen-retrieved by heat treatment in $10 \mathrm{mM}$ citrate buffer for $5 \mathrm{~min}$. To inhibit endogenous peroxidase, sections were treated with $0.3 \%$ hydrogen peroxide for $30 \mathrm{~min}$. After incubation with 5\% BSA for $30 \mathrm{~min}$ to block non-specific binding, sections were incubated with anti-TBX2 antibody (ab33298, Abcam, 1:50 dilution) overnight at $4{ }^{\circ} \mathrm{C}$. The sections were then incubated with horseradish peroxidase (HRP)-conjugated secondary antibody (A0208, Anti-Rabbit IgG, Beyotime, 1:1000 dilution) at room temperature for $1 \mathrm{~h}$ and developed with the DAB kit (Vector Laboratories, Burlingame, CA) followed by counterstained with Mayer's hematoxylin. Section images were obtained using a microscope (Nikon, Japan).

\section{Cell culture}

Human NPC cell lines, C666-1, CNE-1, HONE1, CNE-2 and SUNE-1, were obtained from Shanghai Institutes for Biological Science Cell Bank (Shanghai, China) and cultured in RPMI 1640 medium (Life Technologies, Shanghai, China) supplemented with 10\% fetal bovine serum (FBS, Hyclone, Shanghai, China), $1 \%$ penicillin-streptomycin solution in a $37^{\circ} \mathrm{C}$ incubator containing $5 \% \mathrm{CO}_{2}$. For the utilized NPC cell lines, DNA fingerprinting and profiling were performed every 4 months to confirm the origin of the cell lines, and to distinguish the cell line from cross-contamination. All cell lines were subjected to mycoplasma and microbial contamination examination. Population doubling time, colony forming efficiency, and morphology under phase contrast were also measured every 6 months under defined conditions to confirm the phonotype of cell line.

\section{RNA interference}

Three TBX2 siRNAs (siRNA1: 5'- CCAAAC GCAUGUACAUCCA-3', siRNA2: 5'- CCAUCCUA AACUCCAUGCA-3' and siRNA3: 5'- CACAGCUGA AGAUCGACAA-3') and a non-specific scramble siRNA (siNC) were synthesized by GenePharm (Shanghai, China), and transfected into CNE-1 cells and HONE-1 cells with Lipofectamine 2000 (Invitrogen, Carlsbad, CA) per the manufacture's instruction. Knockdown efficiency was determined by qRT-PCR and Western blotting at $48 \mathrm{~h}$ after transfection.

\section{Cell viability assay}

CNE-1 cells and HONE-1 cells were plated onto 96-well plates at a density of $2 \times 10^{3}$ cells per well and transfected with siRNA1 or siNC. After incubation for 0 , 24, 48 and $72 \mathrm{~h}, 10 \mu \mathrm{L}$ cell counting assay kit-8 (CCK8) solution (Dojindo Laboratories, Japan) was added to all wells and incubated at $37^{\circ} \mathrm{C}$ for another $1 \mathrm{~h}$. The absorbance at $450 \mathrm{~nm}$ was measured using a microplate reader (Labsystems, Helsinki, Finland).

\section{Cell cycle distribution analysis}

Cells were collected at $48 \mathrm{~h}$ after siRNA transfection, washed with PBS and fixed in ice-cold ethanol at -20 ${ }^{\circ} \mathrm{C}$ overnight. The cells were then washed with PBS, and stained with staining solution containing $20 \mu \mathrm{g} / \mathrm{mL}$ propidium iodide (PI, Sigma, St. Louis, MO) and $100 \mu \mathrm{g} / \mathrm{mL}$ RNase (Sigma) for 20 min. DNA content was analyzed with a flow cytometer (BD Biosciences, Franklin Lakes, NJ).

\section{In vitro invasion assays}

Invasion assays were performed using chamber with 8 $\mu \mathrm{m}$ pore filters (Corning, New York, NY) pre-coated with 1 
mg/mL Matrigel (BD Biosciences, Shanghai, China). Briefly, CNE-1 cells and HONE-1 cells were transfected with siRNA1 or siNC. At $24 \mathrm{~h}$ post transfection, the cells were incubated in serum-free medium overnight. The cells were collected and exact $5 \times 10^{4}$ cells in serum-free medium were plated to the upper chamber, while medium containing $10 \% \mathrm{FBS}$ was added to the lower chamber. After $24 \mathrm{~h}$ of incubation, cells on the lower surface of the membrane were fixed with $4 \%$ paraformaldehyde, stained with $0.5 \%$ crystal violet and then counted in five random fields. To block cell proliferation, mitomycin C (5 $\mu \mathrm{g} / \mathrm{mL}$, Sigma, Shanghai, China) was added.

\section{Statistical analysis}

Individual culture dishes or wells were analyzed separately (no pooling of samples was used). In each experiment a minimum of three wells/dishes of each treatment was used. Each experiment was repeated a minimum of three times, in each experiment, the mean value of the repetitions was calculated and this value was used in the statistical analysis. The data was presented as mean \pm standard deviation (SD). One way ANOVA analysis was used to analyze the significance of in vitro experiments. $P$ value less than 0.05 was considered statistically significant.

\section{CONCLUSIONS}

In conclusion, our results demonstrates that the expression of TBX2 is markedly overexpressed in NPC tissues. Knockdown of TBX2 significantly inhibits the NPC cell proliferation and invasion, and induces cell cycle arrest.

\section{Author contributions}

All the listed authors in the study carried out the experiments, participated in the design of the study and performed the statistical analysis, conceived of the study, and helped to draft the manuscript.

\section{ACKNOWLEDGMENTS}

This work is partly supported by the Youth Foundation of "Revitalize and Defend the Key Talent's Subsidy Project" from the Science and Education Department of Health and Family Planning of Suzhou (KJXW2015042), by the Jiangsu University Special Program of Medical Science(JLY20160114), by the grants from the National Natural Science Foundation of China (Nos. 81302195, 31371139, 81571282, 81502162), and grants from Natural Science Foundation of Jiangsu Province (BK20130301), and the National Key Research and Development Program of China (2016YFC1302200).

\section{CONFLICTS OF INTEREST}

The authors declare no conflicts of interests.

\section{REFERENCES}

1. Yau TK, Lee AW, Wong DH, Pang ES, Ng WT, Yeung RM, Soong IS. Treatment of Stage IV(A-B) nasopharyngeal carcinoma by induction-concurrent chemoradiotherapy and accelerated fractionation: impact of chemotherapy schemes. Int J Radiat Oncol Biol Phys. 2006; 66:1004-1010.

2. Young LS, Rickinson AB. Epstein-Barr virus: 40 years on. Nat Rev Cancer. 2004; 4:757-768.

3. Vokes EE, Liebowitz DN, Weichselbaum RR. Nasopharyngeal carcinoma. Lancet. 1997; 350:1087-1091.

4. Jemal A, Bray F, Center MM, Ferlay J, Ward E, Forman D. Global cancer statistics. CA Cancer J Clin. 2011; 61:69-90.

5. Le QT, Tate D, Koong A, Gibbs IC, Chang SD, Adler JR, Pinto HA, Terris DJ, Fee WE, Goffinet DR. Improved local control with stereotactic radiosurgical boost in patients with nasopharyngeal carcinoma. Int J Radiat Oncol Biol Phys. 2003; 56:1046-1054.

6. Abrahams A, Parker MI, Prince S. The T-box transcription factor Tbx2: its role in development and possible implication in cancer. IUBMB Life. 2010; 62:92-102.

7. Gibson-Brown JJ, Agulnik SI, Silver LM, Niswander L, Papaioannou VE. Involvement of T-box genes Tbx2Tbx5 in vertebrate limb specification and development. Development. 1998; 125:2499-2509.

8. Horton AC, Mahadevan NR, Minguillon C, Osoegawa K, Rokhsar DS, Ruvinsky I, de Jong PJ, Logan MP, GibsonBrown JJ. Conservation of linkage and evolution of developmental function within the Tbx $2 / 3 / 4 / 5$ subfamily of T-box genes: implications for the origin of vertebrate limbs. Dev Genes Evol. 2008; 218:613-628.

9. Harrelson Z, Kelly RG, Goldin SN, Gibson-Brown JJ, Bollag RJ, Silver LM, Papaioannou VE. Tbx2 is essential for patterning the atrioventricular canal and for morphogenesis of the outflow tract during heart development. Development. 2004; 131:5041-5052.

10. Borke JL, Chen JR, Yu JC, Bollag RJ, Orellana MF, Isales CM. Negative transcriptional regulation of connexin 43 by Tbx2 in rat immature coronal sutures and ROS 17/2.8 cells in culture. Cleft Palate Craniofac J. 2003; 40:284-290.

11. Chen JR, Chatterjee B, Meyer R, Yu JC, Borke JL, Isales CM, Kirby ML, Lo CW, Bollag RJ. Tbx2 represses expression of Connexin 43 in osteoblastic-like cells. Calcif Tissue Int. 2004; 74:561-573.

12. Jerome-Majewska LA, Jenkins GP, Ernstoff E, Zindy F, Sherr CJ, Papaioannou VE. Tbx3, the ulnar-mammary syndrome gene, and Tbx2 interact in mammary gland development through a p19Arf/p53-independent pathway. Dev Dyn. 2005; 234:922-933.

13. Vance KW, Carreira S, Brosch G, Goding CR. Tbx2 is overexpressed and plays an important role in maintaining proliferation and suppression of senescence in melanomas. Cancer Res. 2005; 65:2260-2268. 
14. Duo S, Tiao-Dong T, Lei Z, Wei W, Hong-Li S, Xian-Wei D. Expression and clinical significance of tbx 2 in pancreatic cancer. Asian Pac J Cancer Prev. 2009; 10:118-122.

15. Sinclair CS, Adem C, Naderi A, Soderberg CL, Johnson M, Wu K, Wadum L, Couch VL, Sellers TA, Schaid D, Slezak $\mathrm{J}$, Fredericksen Z, Ingle JN, et al. TBX2 is preferentially amplified in BRCA1- and BRCA2-related breast tumors. Cancer Res. 2002; 62:3587-3591.

16. Fan W, Huang X, Chen C, Gray J, Huang T. TBX3 and its isoform $\mathrm{TBX} 3+2 \mathrm{a}$ are functionally distinctive in inhibition of senescence and are overexpressed in a subset of breast cancer cell lines. Cancer Res. 2004; 64:5132-5139.

17. Jacobs JJ, Keblusek P, Robanus-Maandag E, Kristel P, Lingbeek M, Nederlof PM, van Welsem T, van de Vijver MJ, Koh EY, Daley GQ, van Lohuizen M. Senescence bypass screen identifies TBX2, which represses Cdkn2a $(\mathrm{p} 19(\mathrm{ARF}))$ and is amplified in a subset of human breast cancers. Nat Genet. 2000; 26:291-299.

18. Han Y, Tu WW, Wen YG, Yan DW, Qiu GQ, Peng ZH, Zhou CZ. Increased expression of TBX2 is a novel independent prognostic biomarker of a worse outcome in colorectal cancer patients after curative surgery and a potential therapeutic target. Med Oncol. 2013; 30:688.

19. Hu B, Mu HP, Zhang YQ, Su CY, Song JT, Meng C, Liu DX. Prognostic significance of TBX2 expression in nonsmall cell lung cancer. J Mol Histol. 2014; 45:421-426.

20. Ismail A, Bateman A. Expression of TBX2 promotes anchorage-independent growth and survival in the p53negative SW13 adrenocortical carcinoma. Cancer Lett. 2009; 278:230-240.

21. Wang B, Lindley LE, Fernandez-Vega V, Rieger ME, Sims $\mathrm{AH}$, Briegel KJ. The $\mathrm{T}$ box transcription factor TBX2 promotes epithelial-mesenchymal transition and invasion of normal and malignant breast epithelial cells. PLoS One. 2012; 7:e41355.

22. Toyoshima H, Hunter T. p27, a novel inhibitor of G1 cyclinCdk protein kinase activity, is related to p21. Cell. 1994; 78:67-74.

23. Bilican B, Goding CR. Cell cycle regulation of the T-box transcription factor tbx2. Exp Cell Res. 2006; 312:2358-2366.

24. Zhu B, Zhang M, Williams EM, Keller C, Mansoor A, Davie JK. TBX2 represses PTEN in rhabdomyosarcoma and skeletal muscle. Oncogene. 2016; 35:4212-4224.
25. Prince S, Carreira S, Vance KW, Abrahams A, Goding CR. Tbx2 directly represses the expression of the p21(WAF1) cyclin-dependent kinase inhibitor. Cancer Res. 2004; 64:1669-1674.

26. Ludtke TH, Farin HF, Rudat C, Schuster-Gossler K, Petry M, Barnett P, Christoffels VM, Kispert A. Tbx2 controls lung growth by direct repression of the cell cycle inhibitor genes Cdkn1a and Cdkn1b. PLoS Genet. 2013; 9:e1003189.

27. Ribeiro I, Kawakami Y, Buscher D, Raya A, RodriguezLeon J, Morita M, Rodriguez Esteban C, Izpisua Belmonte JC. Tbx2 and Tbx3 regulate the dynamics of cell proliferation during heart remodeling. PLoS One. 2007; 2:e398.

28. Zhu B, Zhang M, Byrum SD, Tackett AJ, Davie JK. TBX2 blocks myogenesis and promotes proliferation in rhabdomyosarcoma cells. Int J Cancer. 2014; 135:785-797.

29. Mikule K, Delaval B, Kaldis P, Jurcyzk A, Hergert P, Doxsey S. Loss of centrosome integrity induces p38-p53p21-dependent G1-S arrest. Nat Cell Biol. 2007; 9:160-170.

30. Fresno Vara JA, Casado E, de Castro J, Cejas P, BeldaIniesta C, Gonzalez-Baron M. PI3K/Akt signalling pathway and cancer. Cancer Treat Rev. 2004; 30:193-204.

31. Vleminckx K, Vakaet L Jr, Mareel M, Fiers W, van Roy F. Genetic manipulation of E-cadherin expression by epithelial tumor cells reveals an invasion suppressor role. Cell. 1991; 66:107-119.

32. Cao C, Rioult-Pedotti MS, Migani P, Yu CJ, Tiwari R, Parang K, Spaller MR, Goebel DJ, Marshall J. Impairment of TrkB-PSD-95 signaling in Angelman syndrome. PLoS Biol. 2013; 11:e1001478.

33. Cao C, Huang X, Han Y, Wan Y, Birnbaumer L, Feng GS, Marshall J, Jiang M, Chu WM. Galpha(i1) and Galpha(i3) are required for epidermal growth factor-mediated activation of the Akt-mTORC1 pathway. Sci Signal. 2009; 2:ra17.

34. Zhang YM, Zhang ZQ, Liu YY, Zhou X, Shi XH, Jiang Q, Fan DL, Cao C. Requirement of Galphai1/3-Gab1 signaling complex for keratinocyte growth factor-induced PI3K-AKT-mTORC1 activation. J Invest Dermatol. 2015; 135:181-191. 